\title{
Missense mutations that alter the DNA-binding domain of the MtrR protein occur frequently in rectal isolates of Neisseria gonorrhoeae that are resistant to faecal lipids
}

\author{
William M. Shafer, ${ }^{1,2}$ Jacqueline T. Balthazar, ${ }^{1,2}$ Kayla E. Hagman ${ }^{1}$ and \\ Stephen A. Morse ${ }^{3}$
}

Author for correspondence: William M. Shafer. Tel: +1 404728 7688. Fax: +1 4043292210.
e-mail: wshafer@unix.cc.emory.edu

1 Department of Microbiology and Immunology, Emory University School of Medicine, Atlanta, GA 30322, USA

2 Laboratories of Microbial Pathogenesis, VA Medical Center (Atlanta), Decatur, GA 30033, USA

3 Sexually Transmitted Diseases Research Laboratory, Center for Disease Control and Prevention, Atlanta, GA 30333, USA

\begin{abstract}
Resistance of Neisseria gonorrhoeae to structurally diverse hydrophobic agents (HAs) has been associated with missense or deletion mutations in the mtrR (multiple transferable resistance Regulator) gene of laboratory-derived strains but their prevalence in clinical isolates was heretofore unknown. Since faecal lipids provide strong selective pressure for the emergence of variants resistant to HAs $\left(H^{R}\right)$, the nucleotide sequence of the $m$ trR gene from rectal isolates of $\boldsymbol{N}$. gonorrhoeae, which displayed different levels of HAR $^{R}$, was determined. Compared to the $m$ trR gene possessed by the HA-sensitive strain FA19, each clinical isolate contained mutations in the coding and/or promoter regions of their mtrR gene. A missense mutation in codon 45 (Gly-45 to Asp) was the most common mutation found in the strains studied and impacted the structure of the helix-turn-helix domain of the MtrR protein thought to be important in DNA-binding activity. Two clinical isolates bearing a missense mutation in codon 45 also contained a single basepair deletion in a 13 bp inverted sequence positioned within the mtrR promoter region. Introduction of $m$ trR sequences amplified from the clinical isolates into strain FA19 revealed that acquisition of the single basepair deletion was correlated with high level HA ${ }^{R}$ while mutations in the mtrR-coding region provided for an intermediate level of HAR.
\end{abstract}

Keywords: gonococci, transcriptional regulator, missense mutations, antimicrobial agents, Neisseria gonorrboeae

\section{INTRODUCTION}

The genetic control of multi-antibiotic resistance expressed by Neisseria gonorrboeae, as exemplified by the $m t r$ (multiple transferable resistance) system, is of considerable interest because a single mutation can lead to resistance to not only antibiotics but also antibacterial compounds (e.g. fatty acids and bile salts) that bathe mucosal surfaces. Maness \& Sparling (1973) initially described the mtr system and showed that it mediated resistance to a panel of hydrophobic agents (HAs) including drugs, dyes and detergents. Subsequent reports indicated that such resistant strains accounted for $12.5 \%$ of all clinical isolates (Morse et al., 1982). Moreover, strains displaying hyper-

Abbreviations: CV, crystal violet; Ery, erythromycin; HA, hydrophobic agent; HTH, helix-turn-helix; TX-100, Triton X-100. sensitivity to penicillin and HAs, due to mutations in env loci, often contained a phenotypically suppressed mutation in their $m$ trR gene (Eisenstein \& Sparling, 1978); these strains could serve as genetic donors in the horizontal spread of $\mathrm{HA}^{\mathbf{R}}$ (Shafer et al., 1984).

The $m t r$ system is a multi-gene complex consisting of the $m$ trR gene, encoding the MtrR transcriptional repressor protein (Pan \& Spratt, 1994), and three tandemly linked genes (mtrCDE) that are positioned $250 \mathrm{bp}$ upstream and transcribed divergently from the $m t r R$ gene (Hagman $e t$ al., 1995). The mtrCDE genes constitute a single transcriptional unit and encode proteins (MtrC, MtrD and MtrE) similar to the MexABOprK membrane proteins of Pseudomonas aeruginosa (Poole et al., 1993a), which mediate bacterial resistance to antibiotics by an efflux-based mechanism (Poole et al., 1993b).

Missense mutations in the $m t r R$-coding region (Pan \& 
Spratt, 1994; Hagman et al., 1995), as well as a single basepair deletion in the $m t r R$ promoter region (Hagman $e t$ al., 1995), were able to confer $\mathrm{HA}^{\mathbf{R}}$ when introduced by transformation into the $\mathrm{HA}^{\mathrm{S}}$ strain FA19. Since the frequency and importance of these mutations among clinical isolates was unknown, we determined the nucleotide sequence of $m t r R$ genes from six strains isolated from patients with rectal gonorrhoea. These isolates were chosen for analysis because antibacterial faecal lipids have been proposed to select for $\mathrm{HA}^{\mathrm{R}}$ variants (Morse et al., 1982). The results revealed that missense mutations that cause radical amino acid substitutions within the proposed DNA-binding domain of the MtrR protein of laboratoryderived strains also occur frequently in $\mathrm{HA}^{\mathbf{R}}$ clinical isolates.

\section{METHODS}

Gonococcal strains and growth conditions. The strains employed in this investigation and their levels of resistance to HAs are listed in Table 1. Strains FA171 and BR87 are genetic derivatives of strain FA19 that were constructed in the 1970s (Sparling et al., 1975; Sarubbi et al., 1975). Strain BR87, hypersusceptible to HAs, contains a missense mutation in codon 45 of its $m$ trR gene (Hagman et al., 1995) that is phenotypically suppressed by an unlinked mutation, env-2 (Sarubbi et al., 1975). The presence of this missense mutation in strain BR87 prompted this investigation. Strain FA171 is a transformant of strain FA19. It was constructed (Sparling et al., 1975) using donor DNA from an $\mathrm{HA}^{\mathrm{R}}$ mutant (FA48) derived from an $\mathrm{HA}$ hypersusceptible mutant (FA47) of strain FA19 (Sarubbi et al., 1975). Strains AP776, AP1058, AP1169, AP1192, NRL31115 and NRL31376 were rectal isolates obtained from non-partner homosexual men with gonorrhoea. These isolates were obtained in Seattle, Washington during the period of 1978-1980 and were previously found to be resistant to the antibacterial action of faecal lipids (Morse et al., 1982). They exhibited varying levels of resistance to HAs (Table 1). All strains were grown as $\mathrm{P}^{+} \mathrm{Op}$ variants on GCB agar containing glucose and iron supplements (Shafer et al., 1984) under $3.8 \%(\mathrm{v} / \mathrm{v}) \mathrm{CO}_{2}$ at $37^{\circ} \mathrm{C}$.
Antimicrobial susceptibility testing. The minimal inhibitory concentrations (MIC) of the HAs crystal violet (CV), erythromycin (Ery) and Triton X-100 (TX-100) for the strains studied were determined as described previously (Shafer et al., 1984) and are presented in Table 1.

PCR amplification and DNA sequencing. A chromosomal DNA sequence encompassing the $633 \mathrm{bp} m t r R$ coding region, $120 \mathrm{bp}$ of sequence information past the translational stop codon, and $272 \mathrm{bp}$ of sequence information upstream of the translational start codon was obtained by PCR amplification of chromosomal DNA preparations (McAllister \& Stephens, 1993) using the oligonucleotide primers CEL-1 (5' GACAATGTTCATGCGATGATAGG $3^{\prime}$ ) and KH9\#3 (5' GACGACAGTGCCAATGCAACG $3^{\prime}$ ). PCR amplification was for 30 cycles using a two-step programme consisting of a 1 min denaturation at $95^{\circ} \mathrm{C}$ followed by extension at $60^{\circ} \mathrm{C}$. PCR products for use in sequencing and transformation were purified by agarose gel electrophoresis and electroeluted into TBE buffer $(9 \mathrm{mM}$ Tris, $9 \mathrm{mM}$ boric acid, $2 \mathrm{mM}$ EDTA, $\mathrm{pH} 8.0$ ); at least two independent lots of PCR-amplified DNA were obtained from each strain. DNA sequencing was performed using the above described oligonucleotide primers, labeled with $\left[\gamma_{-}{ }^{32} \mathrm{P}\right]$ ATP (NEN DuPont). The AmpliTaq cycle sequencing kit (Perkin Elmer) was used as recommended by the manufacturer.

Transformation. A $0.5 \mathrm{ml}$ sample of a culture of strain FA19 $\left(\mathrm{P}^{+}\right)$was incubated with $0.05 \mu \mathrm{g}$ of agarose-gel-purified, PCRamplified DNA in transformation broth (Shafer et al., 1984) for $0.5 \mathrm{~h}$ prior to plating onto GCB agar. After incubation for $5 \mathrm{~h}$ at $37{ }^{\circ} \mathrm{C}$ under $3.8 \%(\mathrm{v} / \mathrm{v}) \mathrm{CO}_{2}$, transformants resistant to Ery $\left(0.5 \mu \mathrm{g} \mathrm{ml}^{-1}\right)$ were selected using an agar overlay procedure (Sparling et al., 1975). Transformants were screened for levels of resistance to $\mathrm{CV}$, Ery and TX-100.

\section{RESULTS}

\section{Deduced amino acid sequences of MtrR proteins}

The nucleotide sequences of the mtrR-coding regions from the isogenic gonococcal strains FA19, FA171 and BR87, and the clinical isolates $\mathrm{CH} 95$ and 3035 , were

Table 1. Strains of $N$. gonorrhoeae and susceptibility to HAs

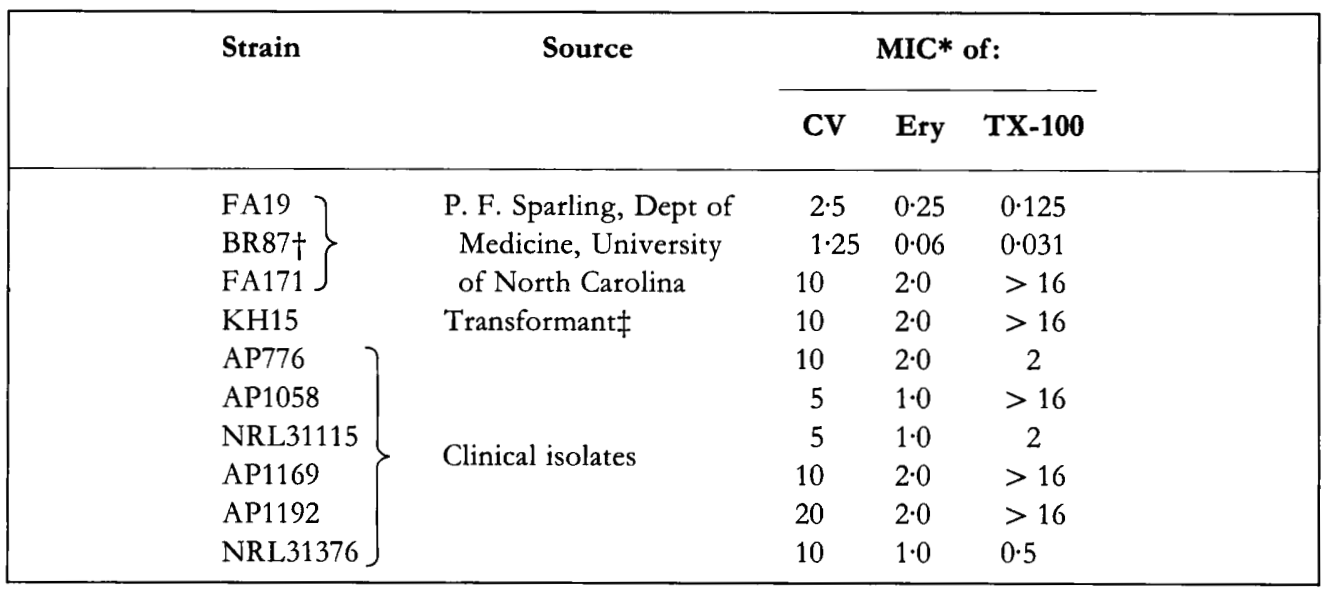

* Expressed as $\mu \mathrm{g} \mathrm{ml}^{-1}$ for $\mathrm{CV}$ and Ery and $\mathrm{mg} \mathrm{ml}^{-1}$ for TX-100.

† The $e n v-2$ mutation renders strain BR87 hypersusceptible to HAs (Sarubbi et al., 1975).

$\ddagger$ Transformant of strain FA19 constructed using a PCR-amplified product from strain FA171 (Hagman et al., 1995). 


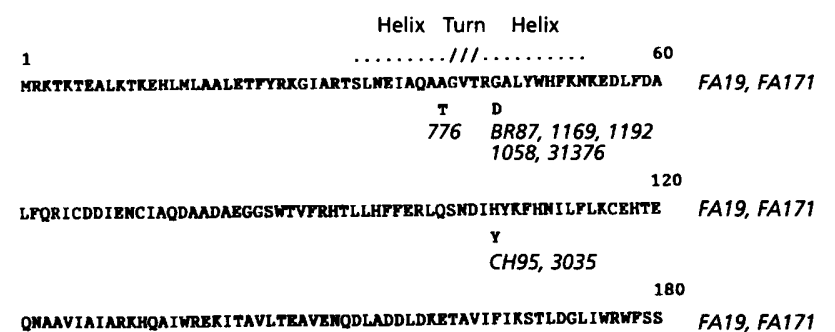

210

GESPDLGKTAPRI IGIMATNLEMHPCLRRX FA19, FA171

Fig. 1. Deduced amino acid sequences of MtrR proteins. The amino acid sequences for the MtrR proteins from strains FA19 and FA171 are identical. Amino acids are shown in the single letter code. The site of amino acid replacements due to missense mutations in codons 40,45 and 105 and strains bearing these (in italics) are shown with the amino acid replacement underneath the amino acid present in the MtrR protein possessed by strains FA19 and FA171. The site of the proposed (Pan \& Spratt, 1994) HTH motif is shown.

previously determined (Hagman et al., 1995; Pan \& Spratt, 1994). This information was used for comparison of their deduced respective MtrR protein sequences with those of the clinical isolates studied herein. As is shown in Fig. 1, the MtrR protein of strain BR87 differed from that of parental strain FA19 by a single amino acid as a result

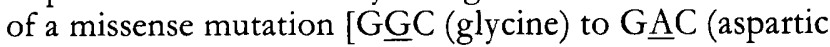
acid)] in codon 45 . This missense mutation is likely to affect MtrR function because it occurs within the second helical domain of the proposed (Pan \& Spratt, 1994) helix-turn-helix (HTH) motif, increasing the helical characteristics of the adjacent turn region. The $m t r R$ coding region from strains $\mathrm{CH} 95$ (isolated in Thailand in 1990) and 3035 (isolated in the UK in 1987) were previously shown (Pan \& Spratt, 1994) to contain an identical missense mutation in codon 105 that replaced histidine with tyrosine at position 105 , which is outside of the HTH motif.

Compared to strain FA19, all six $\mathrm{HA}^{\mathrm{R}}$ rectal isolates possessed nucleotide differences in their $m t r R$-coding sequences. Strain NRL31115 was of particular interest because it contained an 11 bp insert ( $5^{\prime}$ TCTGCGACG$\mathrm{AC} 3^{\prime}$ ) at nucleotide position 204 that represented an exact duplication of nucleotides 193-203 of the mtrR-coding region. This duplication would result in the production of a protein of 117 amino acids with a C-terminal domain that diverges from the FA19 MtrR sequence at amino acid position 69 (Fig. 1) and is truncated by 93 amino acids (data not presented). The other five rectal isolates lacked this duplication but each contained single missense mutations that resulted in radical amino acid replacements in their respective MtrR proteins. A missense mutation in

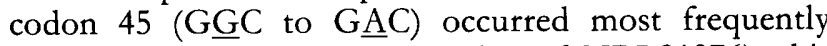
(strains AP1058, AP1169, AP1192 and NRL31376); this mutation was identical to that observed in the $m \operatorname{tr} R$ gene possessed by strain BR87. Strain AP776 contained a missense mutation in codon 40 (GCC to $\underline{\mathrm{ACC}}$ ), which resulted in the replacement of a hydrophobic amino acid
$-35$
$-10$
\# \#

\section{TTGCACGGATAAAAAGTCTTTTTTATAATCCGCCCTCGTCAAA} AACGTGCCTA TTTTTCAGAAAAAATATTAGGCGGGAGCAGTTT

Fig. 2. Nucleotide sequence of the $m$ trR promoter region from strain FA19. The -10 and -35 sites are shown by the double underline. The two start points of transcription (Hagman et al., 1995) are shown (\#) and a possible site of the single bp deletion in the $13 \mathrm{bp}$ inverted repeat sequence (shown in italics) in strains FA171, CH95, AP1169 and AP1192 is shown by the solid rule above the sequence; due to the nature of the repeat sequence, it is impossible to know which of the five ATT basepairs is actually deleted.

(alanine) in the first helical domain of the HTH motif with a hydrophilic amino acid (threonine) (Fig. 1).

\section{Frequency of a deletion mutation in the $m t r R$ promoter region}

Hagman et al. (1995) demonstrated that the MtrR protein possessed by $\mathrm{HA}^{\mathbf{R}}$ strain FA171 had an identical amino acid sequence to that of its parental strain, FA19 (Fig. 1). However, strain FA171 and the clinical isolate CH95 (Hagman et al., 1995) were found to have a single basepair (A/T) deletion in the $13 \mathrm{bp}$ inverted repeat sequence located within the $m t r R$ promoter region (Fig. 2). An examination of the DNA sequence upstream of the $m t r R$ translational start codon in the six clinical isolates revealed that two (strains AP1169 and AP1192) contained this single bp deletion (Fig. 2) in addition to the missense mutation in codon 45 .

\section{Transforming activity of $\mathbf{m t r R}$ genes}

In order to verify that the mutations described above were important in determining $\mathrm{HA}^{\mathbf{R}}$ in gonococci, the $m t r \mathrm{R}$ region was amplified by PCR from strains FA19, FA171, NRL31115, AP776, AP1169 and AP1058 and the gelpurified products were used to transform strain FA19 for increased resistance to HAs; $0.5 \mu \mathrm{g}$ Ery $\mathrm{ml}^{-1}$ was used in the selection. With the exception of the negative control PCR product from strain FA19, all PCR products displayed transforming activity (Table 2). The presence of the donor mutations in representative transformants was confirmed by sequencing PCR-amplifed DNA products (data not presented).

Representative transformants were scored for levels of cross-resistance to CV and TX-100 and the results (Table 2) showed that the transformants expressed either intermediate or high levels of $\mathrm{HA}^{\mathbf{R}}$. Differences in levels of $\mathrm{HA}^{\mathrm{R}}$ expressed by the transformant strains were most apparent with respect to TX-100 resistance $\left(T X-100^{\mathbf{R}}\right)$. Thus, intermediate levels of TX-100 ${ }^{\mathbf{R}}(0 \cdot 5-2 \cdot 0 \mathrm{mg}$ TX$100 \mathrm{ml}^{-\mathbf{1}}$ ) were obtained when the donor DNA possessed only a missense mutation in codon 40 (strain AP776) or codon 45 (strain AP1058) or the nonsense mutation (strain NRL31115). However, donor DNA samples containing the single bp deletion in the $m$ trR promoter 
Table 2. Transforming activity of PCR-amplified $m$ trR genes

\begin{tabular}{|lcccccc|}
\hline $\begin{array}{l}\text { Donor } \\
\text { PCR-DNA }\end{array}$ & $\begin{array}{c}\text { Nonsense } \\
\text { or missense } \\
\text { mutation }\end{array}$ & $\begin{array}{c}\text { Single } \\
\text { bp } \\
\text { deletion }\end{array}$ & $\begin{array}{c}\text { Transformation } \\
\text { frequency }\end{array}$ & \multicolumn{2}{c|}{$\begin{array}{c}\text { MIC* towards } \\
\text { transformants of: }\end{array}$} \\
\cline { 5 - 7 } & - & - & $<10^{-9}$ & NA & NA & NA \\
FA19 & - & + & $4 \times 10^{-4}$ & 10 & $2 \cdot 0$ & $>16$ \\
FA171 & + & - & $8 \times 10^{-5}$ & 5 & $1 \cdot 0$ & 2 \\
NRL31115 & + & - & $4 \times 10^{-5}$ & 5 & $1 \cdot 0$ & 2 \\
AP776 & + & - & $5 \times 10^{-6}$ & 5 & $1 \cdot 0$ & $0 \cdot 5$ \\
AP1058 & + & + & $6 \times 10^{-5}$ & 10 & $2 \cdot 0$ & $>16$ \\
AP1169 & + & + & & TX-100 \\
\hline
\end{tabular}

* Expressed as $\mu \mathrm{g} \mathrm{m}^{-1}$ for $\mathrm{CV}$ and Ery, and $\mathrm{mg} \mathrm{ml}^{-1}$ for $\mathrm{TX}-100$. High-level resistance is defined as TX-100 MIC $>16 \mathrm{mg} \mathrm{ml}^{-1}$ and intermediate resistance is defined as TX-100 MIC 0.5-2.0 $\mathrm{mg} \mathrm{ml}^{-1}$. NA, Not applicable.

† Transformation frequencies were calculated as transformants per mg DNA per $10^{8}$ c.f.u. $\mathrm{ml}^{-1}$.

$\ddagger$ The MIC value for donor strain FA19 is shown in Table 1.

region with (strain AP1169) or without (strain AP171) an accompanying missense mutation in codon 45 were capable of transforming strain FA19 to high level TX$100^{\mathbf{R}}\left(>16 \mathrm{mg} \mathrm{TX}-100 \mathrm{ml}^{-1}\right.$ ). The level of $\mathrm{HA}^{\mathbf{R}}$ expressed by transformants obtained with the FA171, NRL31115, AP776 and AP1169 PCR products resembled that of their respective donor strains (Table 1). However, the level of $\mathrm{HA}^{\mathbf{R}}$ expressed by transformants obtained with the PCR product from strain AP1058 was less than that of the donor strain (Table 2). This difference was more obvious with $\mathrm{TX}-100^{\mathbf{R}}$, suggesting that strain AP1058 contained a second but $m$ tr-independent mechanism for resistance to the membrane-damaging action of this detergent. An $m$ tr-independent mechanism for determining levels of gonococcal resistance to faecal lipids, which exert detergent-like action in membranes, has been previously proposed (McFarland et al., 1983) and is supported by this data.

\section{DISCUSSION}

These results confirm and extend previous studies (Pan \& Spratt, 1994; Hagman et al., 1995) that implicated the MtrR protein as a regulator of $\mathrm{HA}^{\mathbf{R}}$ in gonococci. The similarity between $\mathrm{MtrR}$ and certain transcriptional repressors, notably those belonging to the tetracycline repressor family (Brow et al., 1985), have led to the suggestion that MtrR may function to control expression of genes that are responsible for the efflux of HAs. Indeed, our recent studies (Hagman et al., 1995) indicate that MtrR regulates expression of the tandemly linked $m \operatorname{tr} C D E$ genes because mutations in the $m t r R$-coding or upstream sequences results in enhanced levels of the MtrC lipoprotein. MtrC (Hagman et al., 1995) shares more than $40 \%$ identity at the amino acid level to the MexA (Poole et al., 1993), AcrA (Ma et al., 1993) and EnvC (Klein et al., 1991) lipoproteins that participate in the efflux of antimicrobial agents from $P$. aeruginosa (MexA) and $E$. coli (AcrA and EnvC).
The missense mutation in codon 45 that we identified in four of the six clinical isolates was identical to that observed previously (Hagman et al., 1995) in a laboratoryderived strain (BR87). Since this mutation is phenotypically suppressed in strain BR87 by an unlinked mutation in the env-2 locus (Sarubbi et al., 1975) its significance was unknown. Hence, the presence of this mutation among the clinical isolates studied herein indicates that it is important in $\mathrm{HA}^{\mathrm{R}}$ in vivo. Moreover, this and a second missense mutation in codon 40 , which also results in a radical amino acid substitution within the HTH motif of MtrR, suggests that this domain is important in the ability of MtrR to regulate levels of $\mathrm{HA}^{\mathrm{R}}$ in gonococci. It is possible that amino acid replacements in the first (Ala-40 to Thr) or second (Gly-45 to Asp) helical domains reduces the ability of MtrR to bind to its DNA target site. We hypothesize that this reduction in MtrR binding allows for enhanced expression of the $m \operatorname{tr} C D E$ genes. The mechanism by which the missense mutation in codon 105 (His-105 to Tyr) in the mtrR gene of strains $\mathrm{CH} 95$ and 3035 results in $\mathrm{HA}^{\mathbf{R}}$ is more difficult to understand since the amino acid replacement is outside of the proposed DNA-binding domain of MtrR. However, changes in amino acid sequence downstream of the HTH region could affect tertiary structure or subunit interactions that are important in DNA-binding. The impact of this mutation emphasizes the complexity of MtrR-mediated regulation of $\mathrm{HA}^{\mathrm{R}}$ in gonococci.

High level $\mathrm{HA}^{\mathrm{R}}$ in gonococci due to the mtr system is dependent on a single basepair deletion located within the $m t r R$ promoter region. This deletion is located within a novel 13 bp inverted repeat sequence (Fig. 2); however, the significance of this repeat sequence and the impact of the deletion are not yet clear. Nevertheless, two hypotheses can be advanced, which are not mutually exclusive, that could account for their roles in determining $\mathrm{HA}^{\mathrm{R}}$ in gonococci. First, the inverted repeat sequence could serve as a recognition site for MtrR and loss of a single basepair might reduce binding. Second, by de- 
creasing the spacing between the -10 and -35 regions of the mtrR promoter by a single bp the fidelity of transcription could be affected by this deletion, resulting in loss of mtrR expression. It is important to note that transformants of strain FA19 bearing a null mutation in the $m t r R$ gene exhibited different levels of $\mathrm{HA}^{\mathrm{R}}$ depending on whether they contained an intact $13 \mathrm{bp}$ inverted repeat sequence (Hagman et al., 1995). In this respect, strains bearing both a null mutation in $m t r R$ and the single basepair deletion displayed higher levels of $\mathrm{HA}^{\mathbf{R}}$ than isogenic strains containing the null mutation but having an intact $13 \mathrm{bp}$ inverted repeat. Recent transcriptional studies indicate that this single basepair deletion inhibits expression of $m t r R$ but enhances expression of the mtrCDE gene complex (K. E. Hagman \& W. M. Shafer, unpublished results), a result that is consistent with the notion that the $13 \mathrm{bp}$ inverted repeat sequence is a cisacting transcriptional control element.

Mutations in the $m t r R$ gene capable of transforming strain FA19 for enhanced resistance to HAs have been detected in rectal isolates and in strains isolated from patients with urogenital infections (Pan \& Spratt, 1994; W. M. Shafer and others, unpublished observations), an observation that is consistent with the relatively high frequency at which $\mathrm{HA}^{\mathbf{R}}$ strains are isolated (Morse et al., 1982). The capacity of gonococci to increase $\mathrm{HA}^{\mathrm{R}}$ through mutations in the $m t r R$-coding region or the $m t r R$ promoter region, or by an mtr-independent mechanism, provides this pathogen with several mechanisms to resist toxic agents that bathe certain mucosal surfaces. Whether the different levels of $\mathrm{HA}^{\mathrm{R}}$ afforded by these different genetic mechanisms are important in the ability of gonococci to survive at mucosal sites rich in HAs has yet to be determined.

\section{ACKNOWLEDGEMENTS}

We thank P. F. Sparling for providing strains FA19, FA171 and BR87, L. Jones (Emory University Microchemical Facility) for preparing oligonucleotides, and L. Pucko for help in manuscript preparation. W.M.S. was supported by an Associate Career Scientist award from the VA Medical Research Service. This work was supported by PHS grant AI-21150 and funds from the VA Medical Research Service, both to W.M.S.

\section{REFERENCES}

Brow, M. A. D., Pesin, R. \& Sutcliffe, J. G. (1985). The tetracycline repressor of pSC101. Mol Biol Evol 2, 1-12.

Eisenstein, B. I. \& Sparling, P. F. (1978). Mutations to increased antibiotic sensitivity in naturally-occurring gonococci. Nature 271, 242-244.

Hagman, K. E., Pan, W., Spratt, B. G., Balthazar, J. T., Judd, R. C. \& Shafer, W. M. (1995). Resistance of Neisseria gonorrboeae to antimicrobial hydrophobic agents is modulated by the $\operatorname{mtrCDE}$ efflux system. Microbiology 141, 611-622.

Klein, J. R., Heinrich, B. \& Plapp, R. (1991). Molecular analysis and nucleotide sequence of the $e n \nu C D$ operon of Escherichia coli. Mol \& Gen Genet 230, 230-240.

Ma, D., Cook, D. N., Alberti, M., Pon, N. G., Nikaido, H. \& Hearst, J. E. (1993). Molecular cloning and characterization of $\operatorname{acr} A$ and acrE genes of Eschericbia coli. J Bacteriol 175, 6299-6313.

Maness, M. J. \& Sparling, P. F. (1973). Multiple antibiotic resistance due to a single mutation in Neisseria gonorrboeae. J Infect Dis 128, 321-330.

McAllister, C. F. \& Stephens, D. S. (1993). Analysis in Neisseria meningitidis and other Neisseria species of genes homologous to the FKBP immunophilin family. Mol Microbiol 10, 13-24.

McFarland, L., Mietzner, T. A., Knapp, J. S., Sandstrom, E., Holmes, K. K. \& Morse, S. A. (1983). Gonococcal sensitivity to fecal lipids can be mediated by an $m t r$-independent mechanism. J Clin Microbiol 18, 121-127.

Morse, S. A., Lysko, P. G., McFarland, L., Knapp, J. S., Sandstrom, E., Critchlow, C. \& Holmes, K. K. (1982). Gonococcal strains from homosexual men have outer membranes with reduced permeability to hydrophobic molecules. Infect Immun 37, 432-438.

Pan, W. \& Spratt, B. G. (1994). Regulation of the permeability of the gonococcal cell envelope by the mtr system. Mol Microbiol 11, 769-775.

Poole, K., Heinrichs, D. E. \& Neshat, S. (1993a). Cloning and sequence analysis of an EnvCD homologue in Pseudomonas aeruginosa: regulation by iron and possible involvement in the secretion of siderophore pyoverdine. Mol Microbiol 10, 529-544.

Poole, K., Krebs, K., McNally, C., Neshat, S. (1993b). Multiple antibiotic resistance in Pseudomonas aeruginosa: evidence for involvement of an efflux operon. $J$ Bacteriol 175, 7363-7372.

Sarubbi, F. A., Sparling, P. F., Blackman, E. \& Lewis, E. (1975). Loss of low-level antibiotic resistance in Neisseria gonorrhoeae due to env mutations. J Bacteriol 124, 750-756.

Shafer, W. M., Guymon, L. F., Lind, I. \& Sparling, P. F. (1984). Identification of an envelope mutation $(e n v-10)$ resulting in increased antibiotic susceptibility and pyocin resistance in a clinical isolate of Neisseria gonorrboeae. Antimicrob Agents Chemother 25, 767-769.

Sparling, P. F., Sarubbi, F. A. \& Blackman, E. (1975). Inheritance of low-level resistance to penicillin, tetracycline, and chloramphenicol in Neisseria gonorrboeae. J Bacteriol 124, 740-749.

Received 27 September 1994; revised 8 December 1994; accepted 5 January 1995. 